\title{
Validation of UV-visible aerosol optical thickness retrieved from spectroradiometer measurements
}

\author{
C. Brogniez, V. Buchard, and F. Auriol \\ LOA/CNRS, Université des Sciences et Technologies de Lille, France
}

Received: 18 January 2008 - Published in Atmos. Chem. Phys. Discuss.: 26 February 2008

Revised: 2 July 2008 - Accepted: 7 July 2008 - Published: 12 August 2008

\begin{abstract}
Global and diffuse UV-visible solar irradiances are routinely measured since 2003 with a spectroradiometer operated by the Laboratoire d'Optique Atmosphérique (LOA) located in Villeneuve d'Ascq, France. The analysis of the direct irradiance derived by cloudless conditions enables retrieving the aerosol optical thickness (AOT) spectrum in the $330-450 \mathrm{~nm}$ range. The site hosts also sunphotometers from the AERONET/PHOTONS network performing routinely measurements of the AOT at several wavelengths. On one hand, comparisons between the spectroradiometer and the sunphotometer AOT at $440 \mathrm{~nm}$ as well as, when available, at 340 and $380 \mathrm{~nm}$, show good agreement: in 2003-2005 at $440 \mathrm{~nm}$ the correlation coefficient, the slope and the intercept of the regression line are [0.97, 0.95, 0.025], and in 2006 at 440,380 and $340 \mathrm{~nm}$ they are [0.97, 1.00, -0.013], [0.97, $0.98,-0.007]$, and $[0.98,0.98,-0.002]$ respectively. On the other hand, the AOT's spectral variations have been compared using the Angström exponents derived from AOT data at 340 and $440 \mathrm{~nm}$ for both instruments. The comparisons show that this parameter is difficult to retrieve accurately due to the small wavelength range and due to the weak AOT values. Thus, AOT derived at wavelengths outside the spectroradiometer range by means of an extrapolation using the Angström parameter would have large uncertainties, whereas spectroradiometer's spectral AOT could be used for direct validation of other AOT, such as those provided by satellite instruments.
\end{abstract}

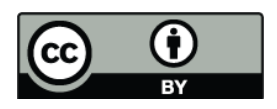

Correspondence to: C. Brogniez (colette.brogniez@univ-lille1.fr)

\section{Introduction}

The determination of spectral aerosol optical properties, such as aerosol optical thickness (AOT) and absorption, is important for climate studies (Forster et al., 2007) and has led to the development of networks such as AERONET/PHOTONS (Holben et al., 1998). In the UV range this characterization is difficult to achieve accurately while it is required to allow for example UV index forecast and surface UV-B irradiance retrieval from satellite instruments such as Total Ozone Mapping Spectrometer and Ozone Monitoring Instrument (OMI) (Wenny et al., 2001; Arola and Koskela, 2004). The AERONET/PHOTONS network operates sun-sky radiometers allowing retrieving the aerosol size distribution, the AOT and the single scattering albedo (SSA) at several wavelengths usually in the 340-1020 nm range (Dubovik et al., 2002). The shortest wavelength at which the SSA is provided is $440 \mathrm{~nm}$ (i.e. in the visible). To determine the wavelength dependence of the AOT and of the SSA in the UV range, it is worthwhile to get them with a spectral step as small as possible. Spectroradiometers that are used for monitoring spectral UV global irradiance at ground level on a horizontal plane can also be employed to obtain spectral direct irradiance from which spectral AOT is inferred. Combining global, diffuse and/or direct irradiance measurements allows also retrieving the SSA (Petters et al., 2003; Bais et al., 2005; Krotkov et al., 2005). The way to determine the direct irradiance is either by using a collimator toward the sun (Gröbner and Meleti, 2004; Kazadzis et al., 2005, 2007; Cheymol et al., 2006), either by measuring the global irradiance and the diffuse irradiance using a shadow disc to hide the sun, the direct irradiance being derived as the difference global minus diffuse irradiances (de la Casinière et al., 2005). In the first technique the field of view of the instrument pointing to the sun is larger than the sun apparent diameter while in the

Published by Copernicus Publications on behalf of the European Geosciences Union. 
second method the shadow disc hides an area larger than the solar disc. Therefore, both techniques introduce a bias in the direct irradiance and thus in the derived AOT. In both cases the bias has to be estimated and to be corrected. The latter technique is used in Villeneuve d'Ascq since 2003 and this work concerns the validation of the AOT retrieval, the SSA retrievals will be the subject of further work.

In Sect. 2 of this paper we describe the spectroradiometer used to perform spectral global and diffuse irradiance measurements and the way the spectral direct irradiance is derived. The methodology for inferring the AOT from this direct irradiance is presented along with a detailed uncertainty budget. Comparisons between the previous products and the AOT provided at the same wavelengths by the sunphotometers of AERONET/PHOTONS network located close to the spectroradiometer are shown in Sect. 3 for several years. Section 4 reports the conclusions.

\section{Instrument and methodology}

The spectroradiometer is located in Villeneuve d'Ascq on the roof of the LOA building $(50.61 \mathrm{~N}, 3.14 \mathrm{E}, 70 \mathrm{~m}$ a.s.l.), in a flat region in the north of France. It is a Jobin-Yvon HD10 thermally regulated, scanning in the wavelength range $290-450 \mathrm{~nm}$, with $0.5 \mathrm{~nm}$ sampling step. Its resolution is about $0.7 \mathrm{~nm}$. Correction of the wavelength misalignment is achieved via a software tool developed at LOA (Houët, 2003), which has been satisfactorily compared to the SHICrivm software (Slaper et al., 1995). Calibration is regularly performed with two standard lamps traceable to NIST (National Institute of Standards and Technology) and NPL (National Physical Laboratory). On average the expanded uncertainty (coverage factor $k=2$ ) on the measured irradiance is estimated to be about $5 \%$ at around $400 \mathrm{~nm}$ and $7 \%$ at around $320 \mathrm{~nm}$ for a high irradiance level (for example for a solar zenith angle $(\mathrm{SZA})=40^{\circ}$ ) and about $7 \%$ and $9 \%$ at 400 and $320 \mathrm{~nm}$ respectively for a low irradiance level (for example for SZA $=70^{\circ}$ ) (Bernhard and Seckmeyer, 1999; Houët, 2003). The instrument has been checked within the QASUME (Quality Assurance of Spectral Ultraviolet Measurements in Europe) project in September 2004 (Gröbner et al., 2006). Since 2003 the instrument performs alternately scans of the global and of the diffuse irradiance every $15 \mathrm{~min}$, from sunrise to sunset. The shadow disc is large enough to cover the solar disc during the scan duration, therefore the measured diffuse irradiance is slightly smaller than the true value and, as stated in the introduction, a correction is needed. Radiances are computed using the radiative transfer code STREAMER (Key, 1999) enabling to estimate the diffuse irradiance that is hidden by the shadower. The input parameters are the temperature and pressure vertical profiles, the AOT, the SSA, and the SZA. Three aerosol models representative of Villeneuve d'Ascq conditions have been studied and a mean correction is made in the data processing to ac- count for the bias (Houët, 2003). The direct irradiance at the time $T$, corresponding to the global measurement, is obtained by removing from this global irradiance the average of the two diffuse irradiances measured at $T-15 \mathrm{~min}$ and $T+15 \mathrm{~min}$. Such a technique requires, of course, stable atmospheric conditions during the period covering the registration of the three spectra. The error introduced by this approximation depends on the aerosol content and on the variation of the SZA during the registration of the spectra. According to Houët (2003), provided the solar zenith angle is smaller than about $60^{\circ}$ the additional maximum error on the direct irradiance is less than $1 \%$ at $340 \mathrm{~nm}$, less than $0.5 \%$ at $380 \mathrm{~nm}$ and less than $0.2 \%$ at $440 \mathrm{~nm}$. In summer, for $\mathrm{SZA}=70^{\circ}$ we obtain $2 \%, 1.5 \%$ and $1 \%$ respectively, and for $\mathrm{SZA}=75^{\circ}$ we have $5 \%, 4 \%$ and $3 \%$ respectively. In winter for $\mathrm{SZA}=70^{\circ}$ the additional error is smaller than $0.2 \%$ at the three wavelengths and for $\mathrm{SZA}=75^{\circ}$ it is smaller than $0.5 \%$. This error can be estimated, and is corrected in the processing. Finally, the shadower adds a negligible uncertainty on the direct irradiance data for $\mathrm{SZA}<60^{\circ}$ and a maximum uncertainty of $1 \%$ at larger SZA.

On clear sky conditions, the total optical thickness at wavelength $\lambda$ is derived from the measurement as follows:

$\delta_{\lambda}^{\mathrm{tot}}=-\cos (\mathrm{SZA}) \times \ln \left(\frac{E_{\lambda}^{\mathrm{dir}}}{E_{\lambda}^{0} \times \cos (\mathrm{SZA})}\right)$

Where $E_{\lambda}^{\text {dir }}$ is the ground-based direct irradiance, $E_{\lambda}^{0}$ is the extraterrestrial flux. Clear sky conditions are selected by means of cloud screening performed using a YES UVB-1 radiometer, close to the spectroradiometer, delivering routine measurements with a 3-min period, enabling to detect any fast variability of the irradiance related to cloud presence. Moreover analyses performed on almucantar measurements in the AERONET/PHOTONS processing are also used to determine if clouds are present or not.

In this work $E_{\lambda}^{0}$ is taken from Thuillier et al. (2003) and is convoluted with the instrument slit function. The retrieved total optical thickness value depends on this reference spectrum and justification of this choice is given below. The aerosol optical thickness is then obtained by removing the contributions of molecules, of ozone and of nitrogen dioxide from the total optical thickness.

The molecular optical thickness is determined following Bodhaine et al. (1999),

$\delta_{\lambda}^{\text {Rayl }}=\sigma_{\lambda}^{\text {Rayl }} \times P_{0} \times \frac{A}{m_{a} g}$,

where $\sigma_{\lambda}^{\text {Rayl }}$ is the molecular scattering cross-section, $P_{0}$ is the pressure at the surface, A is Avogadro's number, $m_{a}$ is the mean molecular weight of dry air and $g$ is the acceleration of gravity. Since $2006 P_{0}$ is measured routinely on the site, while before we use the standard midlatitude atmosphere value (1013 hPa in summer and $1018 \mathrm{hPa}$ in winter). 


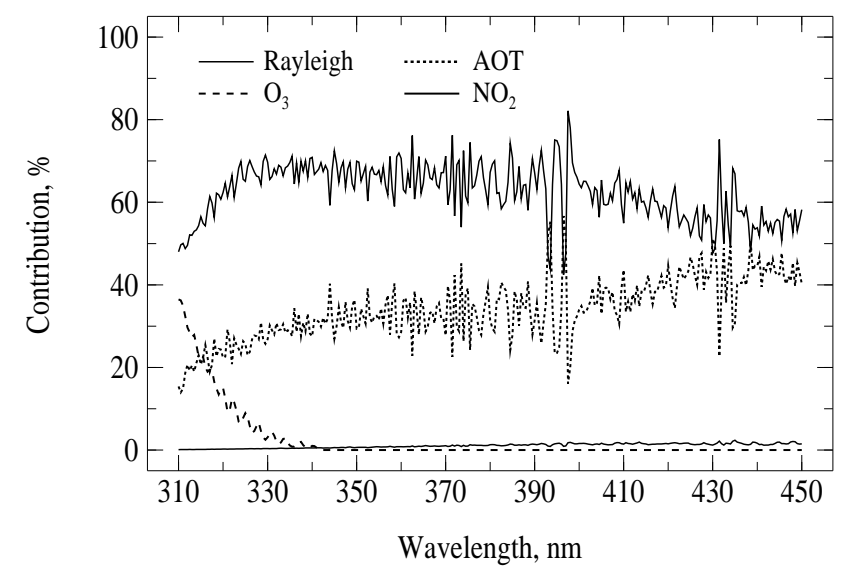

Fig. 1. Contributions of the optical thickness of each species to the total optical thickness measured by the spectroradiometer on 18 July 2006 at 12:30 UTC.

The ozone optical thickness is obtained from

$\delta_{\lambda}^{\mathrm{O}_{3}}=\frac{A \times \sigma_{\lambda}^{\mathrm{O}_{3}}}{V_{m}} \frac{\mathrm{TOC}}{10^{3}}$,

where $V_{m}$ is the molecular volume, TOC is the total ozone column in DU derived from the measured spectrum (Houët and Brogniez, 2004) and $\sigma_{\lambda}^{\mathrm{O}_{3}}$ is the ozone absorption crosssection (taken from Paur and Bass, 1985) convoluted with the instrument slit function. For $\lambda>340 \mathrm{~nm} \sigma_{\lambda}^{\mathrm{O}_{3}}=0$, thus $\delta_{\lambda}^{\mathrm{O}_{3}}=0$. To estimate the contribution of $\mathrm{NO}_{2}$ we need its total column, as for $\mathrm{O}_{3}$ in Eq. (3). For measurements performed before OMI launch we use climatological values from Scanning Imaging Absorption Spectrometer for Atmospheric Chartography (SCIAMACHY) available at http://aeronet.gsfc.nasa. gov/cgi-bin/webtool_opera_v2_new. For measurements performed after September 2004 we take values available in the OMI-NO ${ }_{2}$ data files (http://disc.gsfc.nasa.gov/data/datapool/ OMI). The optical thickness $\delta_{\lambda}^{\mathrm{NO}_{2}}$ is then computed using spectroscopic data from Burrows et al. (1998) convoluted with the instrument slit function.

The contribution of each species to the total optical thickness is shown in Fig. 1 for 18 July 2006, 12:30 UTC. It appears clearly that the ozone contribution becomes significant below $330 \mathrm{~nm}$, and that the $\mathrm{NO}_{2}$ contribution is very small in the whole wavelength range.

Figure 2 shows a spectrum (full line) of AOT obtained on the same day. Important high frequency variations appear in the AOT spectrum, especially in the region of Fraunhofer lines at around 393-397 and $431 \mathrm{~nm}$, indicating that the wavelength shift is not completely corrected in our processing. This phenomenon occurs quite often in our AOT spectra, therefore one has performed a triangular smoothing. Spectra corresponding to smoothing over 2, 4 and $6 \mathrm{~nm}$ (Full Width at Half Maximum, FWHM) are reported on the figure. The smoothing over $4 \mathrm{~nm}$ sounds sufficient to re-

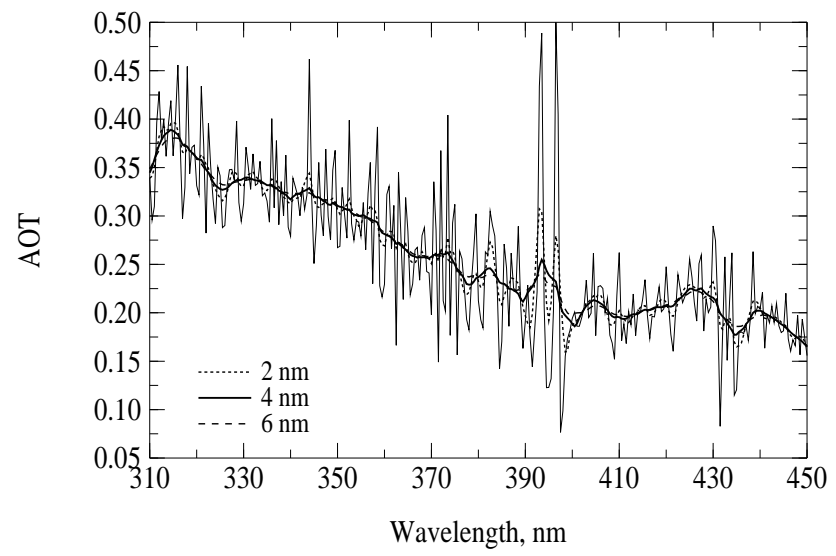

Fig. 2. Spectrum (full thin line) of AOT obtained on 18 July 2006 at 12:30 UTC. Spectra corresponding to triangular smoothing over 2, 4 and $6 \mathrm{~nm}$ are also reported.

move rapid oscillations, so in the following this smoothing is retained though large oscillations remain. These oscillations are smaller when using the reference spectrum provided in the SHICrivm software (Slaper et al., 1995) but above about $400 \mathrm{~nm}$ this reconstructed spectrum is quite different from Thuillier et al. (2003) spectrum and we have observed that it gives AOT at $440 \mathrm{~nm}$ in lesser agreement with AERONET/PHOTONS. Therefore, we have chosen Thuillier et al. (2003) as reference spectrum.

The AOT uncertainty results from uncertainties on $\delta_{\lambda}^{\text {tot }}$, on $\delta_{\lambda}^{\mathrm{Rayl}}$, on $\delta_{\lambda}^{\mathrm{O}_{3}}$ and on $\delta_{\lambda}^{\mathrm{NO}_{2}}$. In the following all uncertainties are considered uncorrelated. It comes from Eq. (1) that

$\Delta \delta_{\lambda}^{\text {tot }}=\cos (\mathrm{SZA}) \times\left[\left(\frac{\Delta E_{\lambda}^{\mathrm{dir}}}{E_{\lambda}^{\mathrm{dir}}}\right)^{2}+\left(\frac{\Delta E_{\lambda}^{0}}{E_{\lambda}^{0}}\right)^{2}\right]^{1 / 2}$

with the relative uncertainty on $E_{\lambda}^{\text {dir }}$ derived from the uncertainties on the measured global and diffuse irradiances (as given above) and the relative uncertainty on $E_{\lambda}^{0}$ about $1.5 \%$ according to Thuillier et al. (2003). From Eq. (2) it appears that the uncertainty $\Delta \delta_{\lambda}^{\text {Rayl }}$ is due to the uncertainty on the Rayleigh scattering cross-section and on the uncertainty on the pressure value at the surface. According to Bodhaine et al. (1999), the relative uncertainty on $\sigma_{\lambda}^{\text {Rayl }}$ is less than $1 \%$. The relative uncertainty on the surface pressure is estimated to $1.5 \%$ when using the standard midlatitude atmosphere (estimated in 2006 by comparing these values and the measured pressure), as before 2006 , and $0.2 \%$ when a measured surface pressure is available, as in 2006. Following Eq. (3) the uncertainty $\Delta \delta_{\lambda}^{\mathrm{O}_{3}}$ is due to the uncertainty on the ozone absorption cross-section, about $2 \%$ (Orphal and Chance, 2003), and to the uncertainty on the ozone content, about $3 \%$ on clear sky days according to Houët and Brogniez (2004). Similarly, the uncertainty $\Delta \delta_{\lambda}^{\mathrm{NO}_{2}}$ is due to about $2 \%$ uncertainty on the $\mathrm{NO}_{2}$ absorption cross-section (Orphal 
Table 1. Uncertainty budget for the spectroradiometer and the sunphotometer at two solar zenith angles and at four wavelengths.

\begin{tabular}{|c|c|c|c|c|c|c|c|c|c|}
\hline \multirow[b]{2}{*}{ Spectro } & \multirow[t]{2}{*}{$\lambda, \mathrm{nm}$} & \multicolumn{2}{|c|}{440} & \multicolumn{2}{|c|}{380} & \multicolumn{2}{|c|}{340} & \multicolumn{2}{|c|}{320} \\
\hline & & $\mathrm{SZA}=40^{\circ}$ & $\mathrm{SZA}=70^{\circ}$ & $\mathrm{SZA}=40^{\circ}$ & $\mathrm{SZA}=70^{\circ}$ & $\mathrm{SZA}=40^{\circ}$ & $\mathrm{SZA}=70^{\circ}$ & $\mathrm{SZA}=40^{\circ}$ & $\mathrm{SZA}=70^{\circ}$ \\
\hline$\Delta \delta_{\lambda}^{\text {tot }}$ & & 0.040 & 0.028 & 0.047 & 0.031 & 0.051 & 0.033 & 0.055 & 0.035 \\
\hline$\Delta \delta_{\lambda}^{\text {Rayl }}$ & $\begin{array}{c}\text { Before } 2006 \\
2006\end{array}$ & \multicolumn{2}{|c|}{$\begin{array}{l}0.0043 \\
0.0024\end{array}$} & \multicolumn{2}{|c|}{$\begin{array}{l}0.0080 \\
0.0044\end{array}$} & \multicolumn{2}{|c|}{$\begin{array}{l}0.0128 \\
0.0071\end{array}$} & \multicolumn{2}{|c|}{$\begin{array}{l}0.0166 \\
0.0092\end{array}$} \\
\hline$\Delta \delta_{\lambda}^{\mathrm{O}_{3}}$ & & \multicolumn{2}{|c|}{0.} & \multicolumn{2}{|c|}{0.} & \multicolumn{2}{|c|}{0.} & \multicolumn{2}{|c|}{$\begin{array}{c}0.007^{*} \\
0.012^{* *}\end{array}$} \\
\hline \multirow[t]{2}{*}{$\Delta(\mathrm{AOT})$ spectro } & Before 2006 & 0.040 & 0.028 & 0.048 & 0.032 & 0.053 & 0.034 & $\begin{array}{c}0.058^{*} \\
0.059^{* *}\end{array}$ & $\begin{array}{c}0.039^{*} \\
0.041^{* *}\end{array}$ \\
\hline & 2006 & 0.040 & 0.028 & 0.047 & 0.031 & 0.052 & 0.033 & $\begin{array}{c}0.056^{*} \\
0.057^{* *}\end{array}$ & $\begin{array}{c}0.037^{*} \\
0.038^{* *}\end{array}$ \\
\hline$\Delta$ (AOT) Sunphotometer & & 0.008 & 0.004 & 0.012 & 0.005 & 0.015 & 0.007 & & \\
\hline
\end{tabular}

${ }^{*}$ For TOC $=250 \mathrm{DU},{ }^{* *}$ for TOC $=450 \mathrm{DU}$

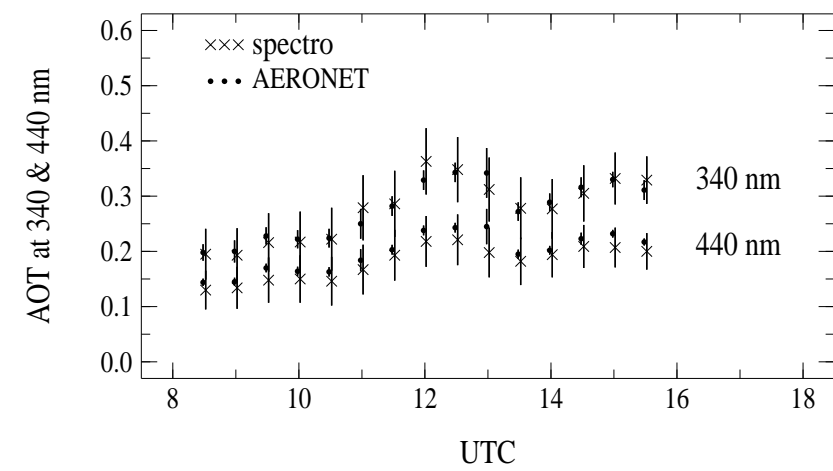

Fig. 3. Daily variations of AOT from the spectroradiometer and from AERONET/PHOTONS at 340 and $440 \mathrm{~nm}$ on 3 July 2006. Vertical bars correspond to AOT uncertainties. (Note that the uncertainties on AOT from AERONET/PHOTONS are sometimes very small).

and Chance, 2003) and to the uncertainty on the $\mathrm{NO}_{2}$ content. This last value is estimated to be about $50 \%$ for OMI data according to a $\mathrm{NO}_{2}$ data quality document (available at http://disc.gsfc.nasa.gov/Aura/OMI/), but since the $\mathrm{NO}_{2}$ contribution is small the exact value uncertainty has a weak importance.

The various uncertainties at three wavelengths are reported in Table 1. The main contribution comes from the spectroradiometer calibration and from the extraterrestrial flux, whatever the wavelength. The resulting AOT uncertainty varies from 0.025 to 0.055 , depending on the wavelength and on the solar elevation.

The shortest wavelength measured by the sunphotometer instruments from AERONET/PHOTONS network operating in Villeneuve d'Ascq before 2006 is $440 \mathrm{~nm}$, while it is $340 \mathrm{~nm}$ since 2006. AOT from these instruments are thus available at visible wavelengths before 2006, and also at 380 and $340 \mathrm{~nm}$ since 2006. The sunphotometer filters at 340 $(\mathrm{FWHM}=2 \mathrm{~nm}), 380$ (4) and $440(10) \mathrm{nm}$ are therefore applied to the spectroradiometer AOT smoothed spectrum to obtain AOT at these three wavelengths for comparison with AOT from AERONET/PHOTONS. Compared to other spectroradiometers such as Brewers, whose largest measurement wavelength is 320 or $365 \mathrm{~nm}$, the advantage of our spectroradiometer is that its spectral range is large enough to avoid extrapolation for comparison with AERONET/PHOTONS AOT at one or several wavelengths in the UV-visible.

Note that the AERONET/PHOTONS processing uses the same molecular scattering cross-sections and for $P_{0}$ NCEP (National Center for Environmental Prediction) 6-h averages or monthly climatology from NCEP/NCAR (National Center for Atmospheric Research) reanalysis. For $\mathrm{O}_{3}$ and $\mathrm{NO}_{2}$ it uses the same absorption cross-sections as we use and for $\mathrm{O}_{3}$ and $\mathrm{NO}_{2}$ total columns it takes monthly climatologies from TOMS and SCIAMACHY respectively. Uncertainties on AOT from AERONET/PHOTONS are estimated equal to $C \times \cos$ (SZA), with C about 0.01 at $440 \mathrm{~nm}, 0.015$ at $380 \mathrm{~nm}$ and 0.02 at $340 \mathrm{~nm}$ (Eck et al., 1999; Hamonou et al., 1999), they are also reported in Table 1 where it appears that they are significantly smaller than spectroradiometer's uncertainties. The data available for this work are of level 2.0 up to end of January 2006 and of level 1.5 after.

\section{Results}

Direct irradiance measurements from the spectroradiometer obtained on cloudless conditions are available since 2003, though not continuously. In the following we have considered separately the year 2006 because 

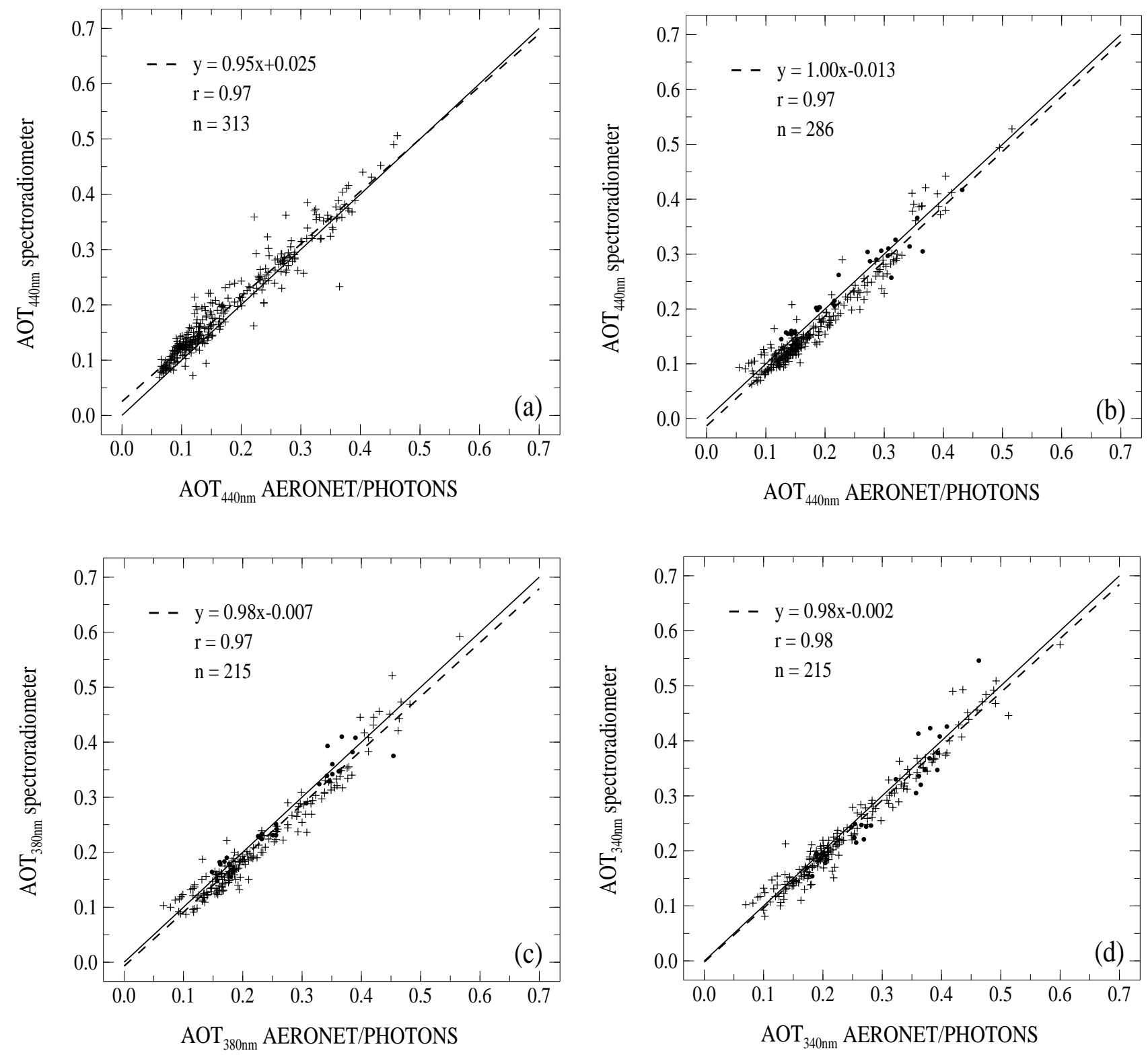

Fig. 4. Scatter plots of AOT from the spectroradiometer versus AOT from AERONET/PHOTONS: (a) in $2003-2005$ at $440 \mathrm{~nm}$; (b) in 2006 at $440 \mathrm{~nm}$; (c) in 2006 at $380 \mathrm{~nm}$; (d) in 2006 at $340 \mathrm{~nm}$. In (b-c-d) dots are for level 2.0, crosses for level 1.5. The equation of the regression line (dash line) and the correlation coefficient are indicated, the solid line is the first bisector, $\mathrm{n}$ is the number of points.

AERONET/PHOTONS data are at level 1.5 except in January, because measurements are generally also available at 340 and $380 \mathrm{~nm}$ and because the pressure at ground level $P_{0}$ is routinely measured. Sunphotometer's AOT used for comparison with spectroradiometer's AOT are mean AOT over the 30 min interval covering the 2 diffuse and the global spectra.

Diurnal variations of the AOT are reported in Fig. 3 for 3 July 2006 at 340 and $440 \mathrm{~nm}$ along with uncertainties. For the spectroradiometer they are estimated following Sect. 2, for the sunphotometer they account for the spread around the mean AOT and for the official uncertainty. At both wavelengths the spectroradiometer's AOT are very close to sunphotometer's AOT and the spectroradiometer captures very well the diurnal variations. Moreover, the sunphotometer data are well within the spectroradiometer uncertainty bars.

Figure $4 \mathrm{a}-\mathrm{d}$ shows scatter plots of AOT retrieved with the spectroradiometer and with the sunphotometer, during 20032005 at $440 \mathrm{~nm}$ and during 2006 at $440-380-340 \mathrm{~nm}$. 

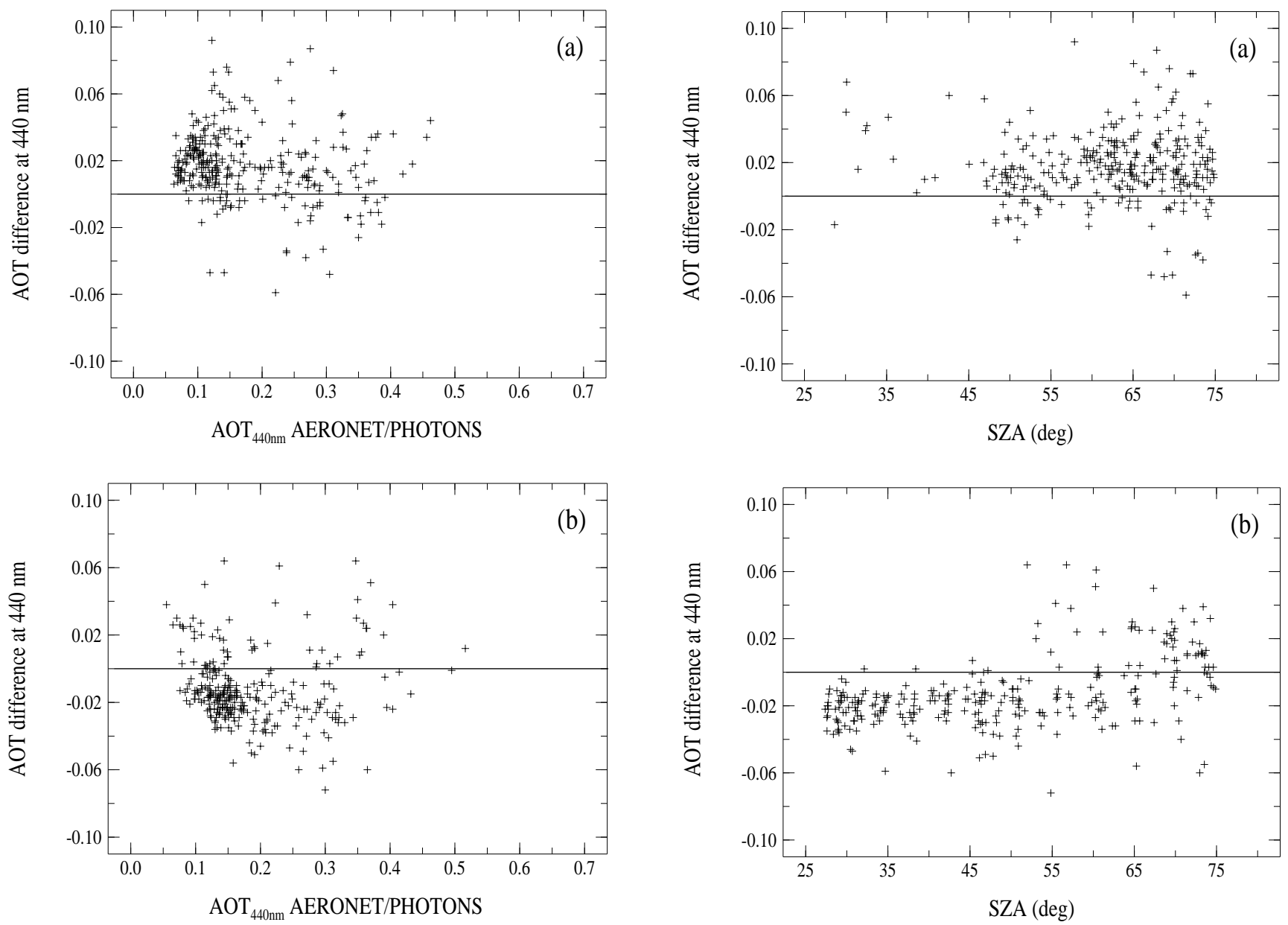

Fig. 5. AOT difference (spectro-AERONET/PHOTONS) at $440 \mathrm{~nm}$ versus AOT at $440 \mathrm{~nm}$ from AERONET/PHOTONS: (a) in 20032005; (b) in 2006.

When looking at AOT at $440 \mathrm{~nm}$ for the two periods (Fig. 4a and b) it appears that on average the spectroradiometer retrieves larger AOT than the sunphotometer in 2003-2005 (slope of the regression line $=0.95$, intercept $=$ 0.025 ), while it is the reverse on 2006 (slope $=1.00$, intercept $=-0.013$ ). As was stated before, 2006 data from AERONET/PHOTONS are of level 1.5 after January instead of level 2.0, thus some changes could occur when the new version will be available. Nevertheless the behaviour of the January pairs (dots) does not differ from the other pairs (crosses). The agreement is also very satisfying at the two other wavelengths (slope $=0.98$, intercept $=-0.007$ at $380 \mathrm{~nm}$ and slope $=0.98$, intercept $=-0.002$ at $340 \mathrm{~nm}$ ). In all cases the correlation is very good (correlation coefficients $\geq 0.97$ ).

Figure 5 shows the AOT difference as function of AOT for 2003-2005 and 2006 at $440 \mathrm{~nm}$. The differences are generally smaller than the spectroradiometer's AOT uncer-

Fig. 6. AOT difference (Spectro-AERONET/PHOTONS) at $440 \mathrm{~nm}$ versus SZA in 2003-2005 (a) and in 2006 (b).

tainty. An AOT effect appears whatever the period and the wavelength, with differences generally smaller at small AOT values. A similar behaviour is observed in 2006 at 380 and $340 \mathrm{~nm}$ (not shown). Figure 6 shows the AOT difference versus SZA for 2003-2005 and 2006 at $440 \mathrm{~nm}$. As observed in Fig. 6b, there exists a SZA effect in 2006 with a larger number of positive difference values for low sun $\left(\mathrm{SZA}>50^{\circ}\right)$. The same effect is observed at $380 \mathrm{~nm}$ but at $340 \mathrm{~nm}$ it is weaker (not shown). In 2003-2005 (Fig. 6a) there is no obvious effect but during that period only few data are available for $\mathrm{SZA}<50^{\circ}$. Small SZA values occur in summer but possible seasonal effects in the differences have not been investigated because clear sky data are not regularly distributed over the year.

An explanation of the bias observed in 2006 could be an underestimation of the shadower correction made using STREAMER, but before trying to improve the correction this bias has to be confirmed when using AERONET/PHOTONS level 2.0 data. Since a large number of the AOT are rather 


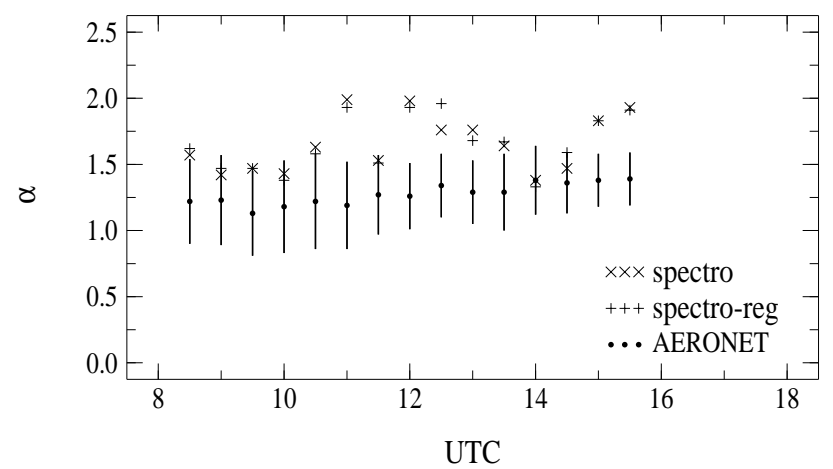

Fig. 7. Daily variations of the Angström exponents retrieved from the spectroradiomer's AOT at 340 and $440 \mathrm{~nm}$, from the regression on the spectroradiometer's AOT in the $330-440 \mathrm{~nm}$ range and from AERONET/PHOTONS's AOT at 340 and $440 \mathrm{~nm}$. Vertical bars correspond to uncertainties on $\alpha$ from AERONET/PHOTONS.

small (in 2003-2005 about $65 \%$ of AOT at $440 \mathrm{~nm} \leq 0.2$, in 2006 about $75 \%$ at $440 \mathrm{~nm}, 60 \%$ at $380 \mathrm{~nm}$ and $45 \%$ at $340 \mathrm{~nm}$ ), a large number of relative differences are very large.

Using a power law for the dependence of AOT on the wavelength, an Angström exponent, called $\alpha_{\text {Spect-reg, }}$, is derived applying a least-squares fit on the spectroradiometer's AOT data in the wavelength range $330-440 \mathrm{~nm}$. The lower limit of this wavelength range is chosen equal to $330 \mathrm{~nm}$ because, as mentioned in section 2 and as seen in Table 1, the effects of molecular scattering and of ozone absorption increase below this value and thus the AOT uncertainty increases. This value of $\alpha_{\text {Spect-reg }}$ is only an estimate of the spectral variations of the AOT since the spectrum exhibits oscillations. Another Angström exponent, $\alpha_{\text {Spect }}$, is derived from the AOT at 340 and $440 \mathrm{~nm}$

$\alpha_{\text {Spect }}=\ln \left(\frac{\mathrm{AOT}_{340}}{\mathrm{AOT}_{440}}\right) / \ln \left(\frac{440}{340}\right)$,

and the uncertainty due to AOT uncertainties is estimated.

$\alpha_{\text {Spect }}$ can be directly compared with $\alpha_{A / P}$, obtained by averaging AERONET/PHOTONS Angström exponents, computed for the same wavelengths as in Eq. (5), during the $30 \mathrm{~min}$ interval. The uncertainty on $\alpha_{A / P}$ accounts for the spread around the mean and for the uncertainty on each value.

Diurnal variations of the three $\alpha$ are shown in Fig. 7 for the same day as in Fig. 3. We have also reported the uncertainties on $\alpha_{A / P}$, but not those on $\alpha_{\text {Spect }}$ since the large relative uncertainties on spectroradiometer's AOT lead to very large uncertainties on $\alpha_{\text {Spect }}$ (about 2 to 5 times AERONET uncertainties). Both spectroradiometer retrievals are very close (while they correspond to slightly different wavelength ranges) whereas there are often large discrepancies with sunphotometer data, from 0.2 up to 0.7 . Thus, even if spectroradiometer's AOT agree quite well with sunphotometer's AOT,

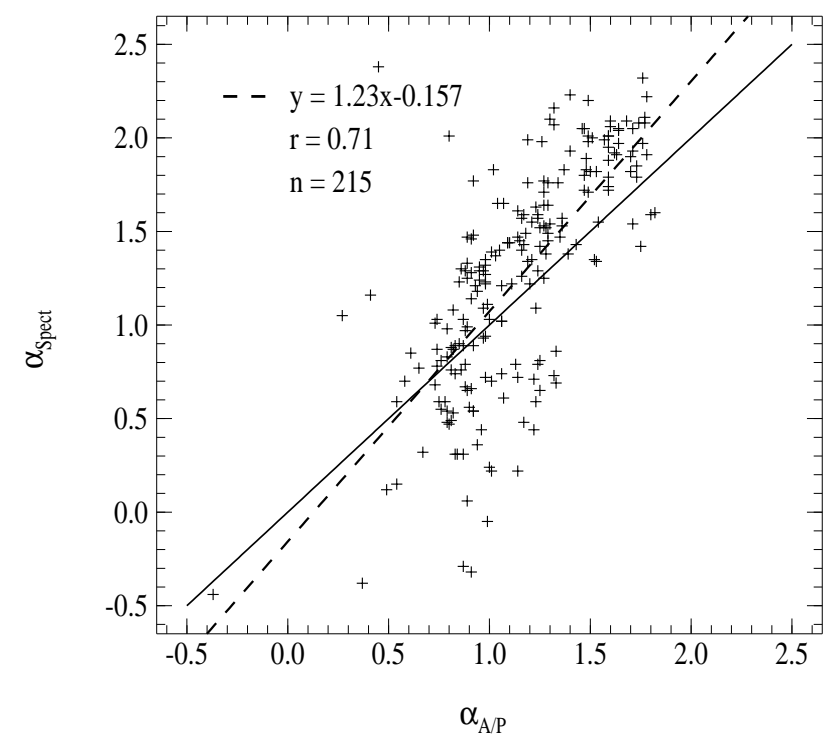

Fig. 8. Scatter plot of the Angström exponent derived from AOT at 340 and $440 \mathrm{~nm}$ for both instruments. The equation of the regression line (dash line) and the correlation coefficient are indicated, the solid line is the first bisector.

as observed in Fig. 3, the small differences existing at both wavelengths lead to large differences in $\alpha$.

Comparison between $\alpha_{\text {Spect-reg }}$ and $\alpha_{\text {Spect }}$ (not shown) gives a good correlation $(r=0.98)$, the slope of the regression line is equal to 0.95 and the intercept is 0.10 , these values can be explained by the difference between the spectral ranges of definition of each $\alpha$. The scatter plot $\alpha_{\text {Spect }}$ versus $\alpha_{A / P}$ in Fig. 8 exhibits a weaker agreement (correlation coefficient $=$ 0.71 , slope $=1.23$, intercept $=-0.157)$, as well as the plot $\alpha_{\text {Spect-reg versus } \alpha_{A / P} \text { (not shown) demonstrating that } \alpha \text { re- }}$ trieval from the spectroradiometer measurements is not very satisfying.

In addition to the low AOT's values at both wavelengths leading to large relative uncertainties on AOT, the rather large uncertainties on $\alpha_{A / P}$ are also explained by the small wavelength range of definition and thus $\alpha_{A / P}$ is also difficult to retrieve accurately.

As observed in Fig. 9 there is a correlation between the AOT and $\alpha_{A / P}$. Small AOT values are obtained for large $\alpha_{A / P}$, i.e. for small aerosols. Figure 10 shows that there is also a correlation between the AOT difference and $\alpha_{A / P}$. Small AOT difference values are obtained for large $\alpha_{A / P}$, i.e. for small aerosols, confirming the AOT effect seen in Fig. 5 (smaller AOT differences at small AOT). A similar behaviour is observed for the AOT differences at 340 and $380 \mathrm{~nm}$ (not shown). This phenomenon could be an effect of the increasing uncertainty on $\alpha_{A / P}$ when the AOT are small, i.e. when the AOT relative uncertainties are large, it needs confirmation with additional measurements. 


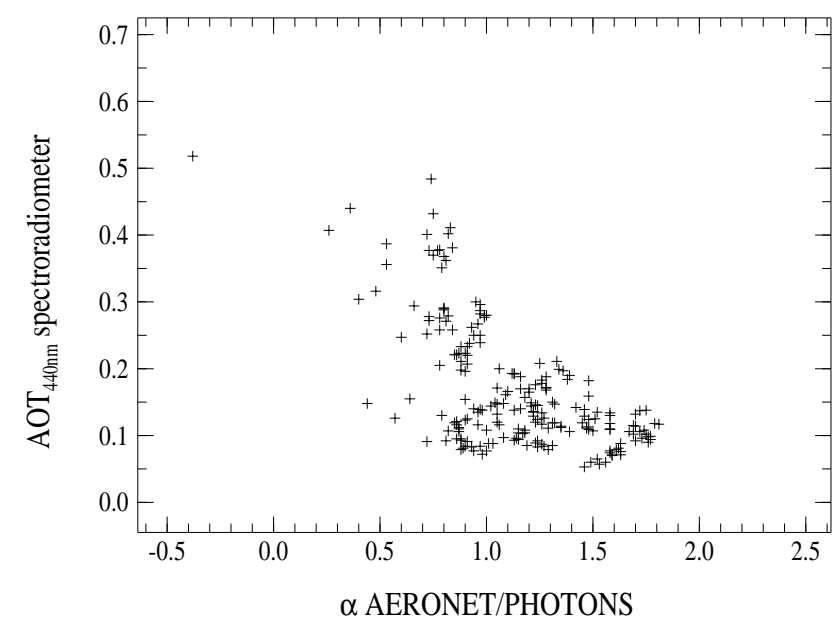

Fig. 9. Spectroradiometer's AOT at $440 \mathrm{~nm}$ versus the AERONET/PHOTONS Angström exponent.

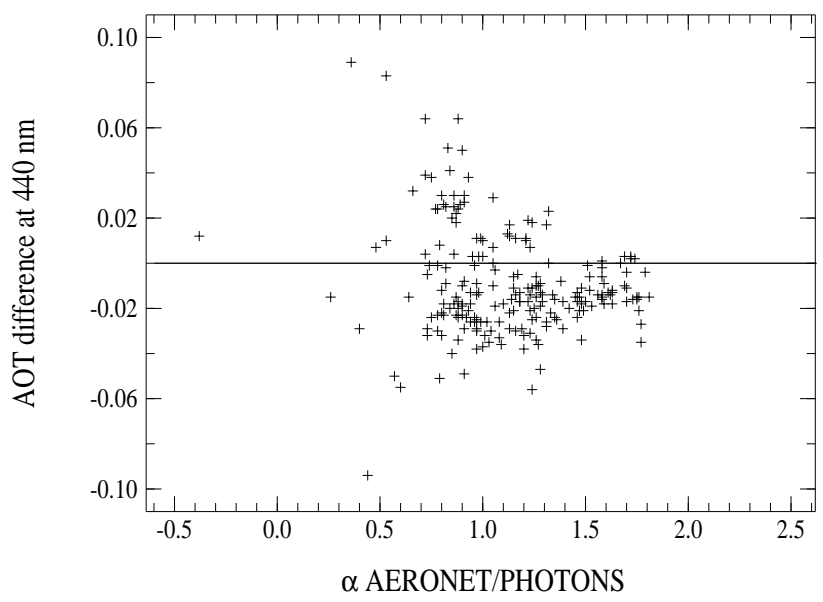

Fig. 10. AOT difference at $440 \mathrm{~nm}$ (SpectroAERONET/PHOTONS) versus the AERONET/PHOTONS Angström exponent.

\section{Conclusions}

Global and diffuse UV-visible spectral irradiance measurements, performed with a spectroradiometer in $\mathrm{VdA}$, have been used to derive the direct spectral irradiance. Under cloudless conditions, the spectral AOT has been inferred from these data. The retrieved AOT at 440, 380 and $340 \mathrm{~nm}$ have been compared with AOT obtained with the sunphotometers of the AERONET/PHOTONS network operating close to the spectroradiometer. The comparisons show good agreement with high correlation coefficients $(\geq 0.97)$, slopes of the regression lines close to 1 and intercepts very small. Moreover for SZA smaller than $65^{\circ}$, the differences are generally smaller than the uncertainties on the spectroradiometer's AOT. These results are satisfying accounting for the as- sumption made on the atmospheric conditions stability (including aerosol stability) during the registration of the spectra.

This validation excercise has been extended to the AOT spectral variations by means of the Angström exponent, computed from AOT at 340 and $440 \mathrm{~nm}$. The comparison of the exponents retrieved from each instrument is less satisfying that AOT comparison, demonstrating that this parameter is difficult to retrieve accurately due to the weak AOT and to the small wavelength range of definition. Thus, AOT derived at wavelengths outside the spectroradiometer range by means of this Angström parameter would have rather large uncertainties, whereas, spectroradiometer's spectral AOT could be used for direct validation of AOT provided by satellite instruments.

Therefore, we plan to use our ground-based spectral AOT measurements to validate OMI retrievals. Next we intend to infer the SSA from the global and diffuse measurements to characterize the aerosol absorption in the UV.

Acknowledgements. We thank L. Blarel and T. Podvin from the PHOTONS team for their help in selecting the data. We thank also O. Dubovik, P. Goloub and S. Smirnov for fruitful discussions.

The site is supported by CNES within the french program TOSCA.

The figures were drawn using the Mgraph package developed at LOA by L. Gonzalez and C. Deroo:

http://www-loa.univ-lille1.fr/Mgraph.

Edited by: M. Blumthaler

\section{References}

Arola, A. and Koskela, T.: On the sources of bias in aerosol optical depth retrieval in the UV range, J. Geophys. Res., 109, D08209, doi:10.1029/2003JD004375, 2004.

Bais, A., Kazantzidis, A., Kazadzis, S., Balis, D., Zerefos, C., and Meleti, C.: Deriving an effective aerosol single scattering albedo from spectral surface UV irradiance measurements, Atmos. Environ., 39, 1093-1102, 2005.

Bernhard, G. and Seckmeyer, G.: Uncertainty of measurements of spectral solar UV irradiance, J. Geophys. Res., 104, $14321-$ 14345, 1999.

Bodhaine, B. A., Wood, N. B., Dutton, E. G., and Slusser, J. R.: On Rayleigh Optical Depth Calculations, J. Atmos. Oceanic Technol., 16, 1854-1861, 1999.

Burrows, J. P., Dehn, A., Deters, B., Himmelmann, S., Richter, A., Voigt, S., and Orphal, J.: Atmospheric Remote-Sensing Reference Data from GOME: 1. Temperature-Dependent Absorption Cross Sections of $\mathrm{NO}_{2}$ in the 231-794 nm Range, J. Quant. Spectrosc. Radiat. Transfer, 60, 1025-1031, 1998.

Cheymol, A., De Backer, H., Josefsson, W., and Stubi, R.: Comparison and validation of the aerosol optical depth obtained with the Langley plot method in the UV-B from Brewer ozone Spectrophotometer measurements, J. Geophys. Res, 111, D16202, doi:10.1029/2006JD007131, 2006.

de La Casinière, A., Cachorro, V., Smolskaia, I., Lenoble, J., Sorribas, M., Houët, M., Massot, O., Anton, M., and Vilaplana, 
J. M.: Comparative measurements of total ozone amount and aerosol optical depth during a campaign at El Arenosillo, Huelva, Spain, Ann. Geophys., 23, 3399-3406, 2005, http://www.ann-geophys.net/23/3399/2005/.

Dubovik, O., Holben, B., Eck, T. F., Smirnov, A., Kaufman, Y. J., King, M. D., Tanré, D., and Slutsker, I.: Variability of absorption and optical properties of key aserosol types observed in worldwide locations, J. Atmos. Sci., 59, 590-608, 2002.

Eck, T. F., Holben, B. N., Reid, J. S., Dubovik, O., Smirnov, A., O'Neill, N. T., Slutsker, I., and Kinne, S.: Wavelength dependence of the optical depth of biomass burning, urban, and desert dust aerosols, J. Geophys. Res, 104(D24), 31 333-31 349, 1999.

Forster, P., Ramaswamy, V., Artaxo, P., et al.: Changes in Atmospheric Constituents and in Radiative Forcing, in: Climate Change 2007: The Physical Science Basis, Contribution of Working Group I to the Fourth Assessment Report of the Intergovernmental Panel on Climate Change, edited by: Solomon, S., Qin, D., Manning, M., Chen, Z., Marquis, M., Averyt, K. B., Tignor, M., and Miller, H. L., Cambridge University Press, Cambridge, UK and New York, NY, USA, IPCC Report, http: //www.ipcc.ch/ipccreports/ar4-syr.htm, 2007.

Gröbner, J. and Meleti, C.: Aerosol optical depth in the UVB and visible wavelength range from Brewer spectrophotometer direct irradiance measurements: 1991-2002, J. Geophys. Res., 109, D09202, doi:10.1029/2003JD004409, 2004.

Gröbner, J., Blumthaler, M., Kazadzis, S., Bais, A., Webb, A., Schreder, J., Seckmeyer, G., and Rembges, D.: Quality assurance of spectral solar UV measurements: results from $25 \mathrm{UV}$ monitoring sites in Europe, 2002 to 2004, Metrologia, 43, S66S71, doi:10.1088/0026-1394/43/2/S14, 2006.

Hamonou, E., Chazette, P., Balis, D., Dulac, F., Schneider, X., Galani, E., Ancellet, G., and Papayannis, A.: Characterization of the vertical structure of Saharan dust export to the Mediterranean basin, J. Geophys. Res., 104(D18), 22 257-22 270, 1999.

Houët, M.: Spectroradiométrie du rayonnement Solaire UV au sol: Améliorations apportées à l'instrumentation et au traitement des mesures. Analyse pour l'évaluation du contenu atmosphérique en ozone et en aérosols, Ph.D. thesis, Univ. of Lille, France, 2003.

Houët, M. and Brogniez, C.: Ozone column retrieval from solar UV irradiance measurements at ground level: sensitivity tests and uncertainty estimation, J. Geophys. Res., 109, D15302, doi:10.1029/2004JD004703, 2004.

Holben, B. N., Eck, T. F., Slutsker, I., Tanré, D., Buis, J. P., Setzer, A., Vermote, E., Reagan, J. A., Kaufman, Y. J., Nakajima, T., Lavenu, F., Jankowiak, I., and Smirnov A.: AERONET - A federated instrument network and data archive for aerosol characterization, Rem. Sens. Environ., 66, 1-6, 1998.
Kazadzis, S., Bais, A., Amiridis, V., Balis, D., Meleti, C., Kouremeti, N., Zerefos, C. S., Rapsomanikis, S., Petrakakis, M., Kelesis, A., Tzoumaka, P., and Kelektsoglou, K.: Nine years of UV aerosol optical depth measurements at Thessaloniki, Greece, Atmos. Chem. Phys., 7, 2091-2101, 2007, http://www.atmos-chem-phys.net/7/2091/2007/.

Kazadzis, S., Bais, A., Kouremeti, N., Gerasopoulos, E., Garane, K., Blumthaler, M., Schallhart, B., and Cede, A.: Direct spectral measurements with a Brewer spectroradiometer: absolute calibration and aerosol optical depth retrieval, Appl. Optics, 44(9), 1681-1690, 2005.

Key, J.: STREAMER user's guide, Technical report 96-01, Department of Geography, Boston University, 1999.

Krotkov, N., Bhartia, P. K., Herman, J., Slusser J., Scott, G., Labow, G., Vasilkov, A. P., Eck, T. F., Dubovik, O., and Holben, B. N.: Aerosol ultraviolet absorption experiment (2002 to 2004), Part 2: absorption optical thickness, refractive index, and single scattering albedo, Opt. Eng., 44(4), doi:10.1117/1.1886819, 2005.

Orphal, J. and Chance, K.: Ultraviolet and visible absorption crosssections for HITRAN, J. Quant. Spectrosc. Radiat. Transfer, 82, 491-504, 2003.

Paur, R. J. and Bass, A. M.: The ultraviolet cross sections of ozone. II, Results and temperature dependence, in: Atmospheric Ozone, Proceedings of the Quadriennal Ozone Symposium, edited by: Zerefos, C. and Ghazi, A., 611-616, 1985.

Petters, J. L., Saxena, V. K., Slusser, J. R., Wenny, B. N., and Madronich, S.: Aerosol single scattering albedo retrieved from measurements of surface UV irradiance and a radiative transfer model, J. Geophys. Res., 108(D9), 4288, doi:10.1029/2002JD002360, 2003.

Slaper, H., Reinen, H., Blumthaler, M., Huber, M., and Kuik, F.: Comparing ground-level spectrally resolved solar UV measurements using various instruments: a technique resolving effects of wavelength shift and slit width, Geophys. Res. Lett., 22, 27212724, 1995.

Thuillier, G., Hersé, M., Labs, D., Foujols, T., Peetermans, W., Gillotay, D., Simon, P. C., and Mandel, H.: The solar spectral irradiance from 200 to $2400 \mathrm{~nm}$ as measured by the SOLSPEC spectrometer from the ATLAS and EURECA missions, Sol. Phys., 214, 1-22, 2003.

Wenny, B. N., Saxena, V. K., Frederick, J. E.: Aerosol optical depth measurements and their impact on surface levels of ultraviolet-B radiation, J. Geophys. Res, 106(D15), 17311-17319, 2001. 